Volume : 6

Nomor : 2

Bulan : November

Tahun : 2020

\title{
Upaya Peningkatan Pengetahuan dan Keterampilan Materi Tata Cara Pengurusan Jenazah Menggunakan Metode Visualisation, Auditory, Kinestetic (VAK)
}

\author{
Mu'tamidah \\ MAN 2 Wonosobo \\ Pos-el: mutamidah@gmail.com
}

DOI: $10.32884 /$ ideas.v6i4.314

\begin{abstract}
Abstrak
Bagi manusia proses kematian mengandung konsekuensi diselenggarakannya proses pengurusan jenazah, tetapi pengetahuan dan keterampilan tata cara pengurusan jenazah siswa masih kurang. Oleh karena itu, penelitian ini bertujuan untuk meningkatkan pengetahuan dan keterampilan siswa tentang tata cara pengurusan jenazah dengan menggunakan metode VAK (Visualisation, Auditory, Kinestetic). Penelitian ini merupakan penelitian tindakan (action research) yang dilaksanakan di kelas X IPA 6 MAN 2 Wonosobo pada bulan Februari sampai Mei 2019. Penelitian ini terdiri dari dua siklus. Masing-masing siklus terdiri dari dua pertemuan. Hasil belajar dan aktivitas belajar siswa berdasarkan hasil penelitian mengalami peningkatan sejak tahap prasiklus/studi pendahuluan hingga berakhirnya siklus 2 dari 47,37\% yang mengalami ketuntasan pada tahap prasiklus menjadi 60,53\% pada siklus 1 dan 92,11\% pada siklus 2. Aktivitas belajar diukur dengan kinerja kelompok yang meningkat dari siklus 1 ke siklus 2. Dengan demikian, dapat disimpulkan bahwa penerapan metode VAK dapat meningkatkan aktivitas dan hasil belajar siswa.
\end{abstract}

Kata Kunci

Pengetahuan, keterampilan, metode VAK, materi tata cara pengurusan jenazah

\begin{abstract}
For humans, the process of death carries the risk of carrying out the process of taking care of the corpse, but unfortunately the knowledge and skills of students on how to handle the bodies of corpses are still lacking. Therefore, this study aims to increase student's skills and knowledge about the procedures for caring for corpses using the VAK (Visualization, Auditory, Kinesthetic) method. This research is an action research that was conducted in class X IPA 6 MAN 2 Wonosobo from February to May 2019. The study consisted of two cycles and each cycle consisted of two meetings. Learning outcomes and student learning activities based on research results have increased since the pre-cycle/preliminary study stage until the end of cycle 2 from $47.37 \%$ who experienced completeness in the pre-cycle stage to $60.53 \%$ in cycle 1 and $92.11 \%$ in cycle 2 Learning activities are measured by group performance which increases from cycle 1 to cycle 2. Thus it can be ignored that the application of the VAK method can increase student activity and learning outcomes.
\end{abstract}

Keywords

Knowledge, skill, VAK method, material procedures for handling the corpse

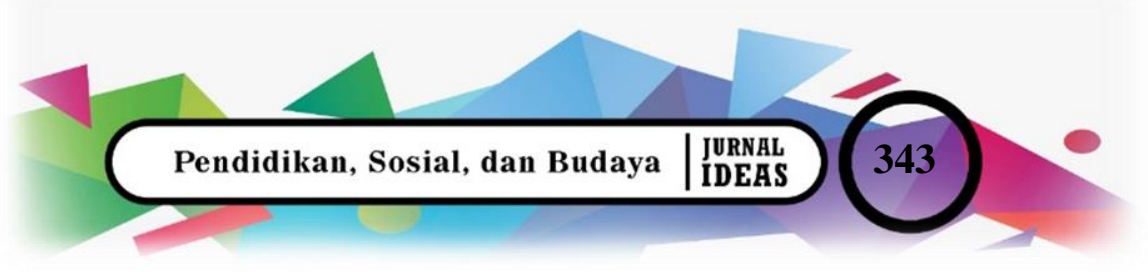


그 E-ISSH: 2656-940X

(D) P-ISSH: 2442-367K

URL:jurnal.ideaspublishing.co.id
Volume : 6

Nomor : 2

Bulan : November

Tahun : 2020

\section{Pendahuluan}

Mata pelajaran Fikih merupakan mata pelajaran yang mempelajari hukum-hukum atau syariat Islam, salah satunya adalah syariat tentang tata cara pengurusan jenazah. Adapun hukum pengurusan jenazah adalah fardhu kifayah. Artinya, apabila sebagian masyarakat telah melaksanakannya, maka telah gugur kewajiban atas yang lain. Namun demikian, keterampilan dan pengetahuan tentang teknik-teknik atau tata cara pengurusan jenazah adalah keterampilan yang hendaknya dikuasai oleh setiap muslim. Pada dasarnya, setiap kita akan berhadapan dengan hal ini, khususnya terkait dengan keluarga kita. Sayangnya, sebagian besar menganggap enteng masalah ini karena hukumnya yang fardhu kifayah. Masyarakat cenderung menyerahkan urusan penyelenggaraan jenazah pada tokoh adat, kiai, atau ulama yang ada di lingkungan mereka.

Jika di lingkungan sekolah, maka dapat dilihat bahwa minat belajar siswa terhadap materi tata cara pengurusan jenazah juga kurang. Hasil wawancara yang telah dilakukan menunjukkan bahwa selama studi pendahuluan, diketahui bahwa beberapa siswa merasa malas belajar tentang tata cara pengurusan jenazah karena hal ini identik dengan mayat. Ada rasa takut dan keengganan untuk belajar karena mereka berpikir itu tugas kiai atau tokoh adat saja. Oleh karena itu, tidak mengherankan jika tingkat ketuntasan siswa pada ulangan harian pada materi ini juga rendah. Dari 38 siswa di kelas X MIA 6, hanya 47,3\% yang mencapai nilai KKM (75) atau hanya 18 siswa. Kurang dari setengah jumlah siswa yang ada di kelas.

Ketika seorang muslim meninggal dunia, maka ada empat kewajiban yang harus disegerakan atas jenazahnya, yaitu memandikan, mengafani, menyalatkan, dan menguburkan. Sayangnya, pengetahuan siswa tentang mekanisme/tata cara, baik itu saat memandikan, mengafani, menyalatkan, maupun menguburkan masih kurang. Penguasaan teori yang kurang menyebabkan kemampuan siswa untuk mempraktikkan tata cara pengurusan jenazah juga rendah.

Teori merupakan sebuah pengetahuan yang menjadi titik awal dalam melakukan kegiatan praktik (Jarvis, 2012). Oleh karena itu, penelitian ini berusaha untuk merangkum upaya untuk meningkatkan pengetahuan (teori) dan keterampilan (skill/psikomotorik) tata cara pengurusan jenazah menggunakan satu metode yang disebut VAK (Visualisation, Auditory, Kinestetic). 
Volume : 6

Nomor : 2

Bulan : November

Tahun : 2020

Metode pembelajaran visual, auditory, kinestetic adalah metode pembelajaran yang mengkombinasikan ketiga gaya belajar, yaitu visual atau melihat, auditory atau mendengarkan, dan kinestetic atau keterlibatan emosi melalui berbagi gerakan setiap individu dengan cara memanfaatkan potensi yang telah dimiliki dengan melatih, kemudian mengembangkannya agar semua kebiasaan belajar peserta didik terpenuhi (Sugiyanto, 2008). Dengan penerapan metode ini, diharapkan pengetahuan dan keterampilan siswa tentang materi tata cara pengurusan jenazah pada kelas X IPA 6 MAN 2 Wonosobo tahun pelajaran 2018/2019 akan meningkat.

Beberapa penelitian yang telah dilakukan antara lain "Penerapan Strategi Pembelajaran Langsung dengan Metode Drill untuk Meningkatkan Aktivitas Belajar dan Keterampilan Pelaksanaan Ibadah Pokok Bahasan Pengurusan Jenazah di MTs Al-Ma'shum Rantauprapat Labuhanbatu" oleh Harahap dkk. (2017). Dari hasil penelitian disimpulkan bahwa dengan pembelajaran langsung menggunakan metode drill (latihan), aktivitas dan keterampilan belajar siswa pada materi tata cara pengurusan jenazah semakin meningkat. Selain itu, ada juga penelitian yang dilakukan oleh Syahidah (2020) yang berupaya meningkatkan prestasi belajar pengurusan jenazah dengan metode demonstrasi. Kedua penelitian memiliki materi kajian yang sama, yaitu membahas materi tata cara pengurusan jenazah, yang membedakan adalah pada metode yang dipilih. Penelitian ini sendiri mencoba meningkatkan pengetahuan dan keterampilan belajar materi tata cara pengurusan jenazah dengan menggunakan tiga modalitas belajar siswa, yaitu audio, visual, dan kinestetik dengan metode VAK.

\section{Metode}

Penelitian ini adalah penelitian tindakan (action research) yang dilaksanakan di kelas X IPA 6 MAN 2 Wonosobo, Jalan Dieng Km 5, Desa Krasak, Kecamatan Mojotengah, Wonosobo, pada bulan Februari sampai dengan Mei 2019. Objek penelitian terdiri dari siswa kelas X IPA 6 yang berjumlah 38 orang dan guru Fikih sebagai peneliti sekaligus objek penelitian. Penelitian menggunakan metode VAK (Visualisation, Auditory, Kinestetic) yang terbagi dalam dua siklus, di mana masing-masing siklus terdiri dari dua kali pertemuan. Evaluasi hasil belajar dilakukan di akhir siklus 1 dan siklus 2, sedangkan aktivitas belajar diamati pada setiap pertemuan. 
Data keterampilan diperoleh dari hasil observasi dengan dibantu oleh kolaborator. Beberapa parameter yang diamati dari keterampilan tata cara pengurusan jenazah adalah tata cara mulai dari memandikan, mengafani, menyalatkan, dan menguburkan. Praktik ini dilakukan secara berkelompok yang terdiri dari 4-5 siswa dengan salah satu siswa di masing-masing kelompok berperan sebagai si mayat. Diamati kebenaran dan kelancaran langkah yang dilakukan, serta kebenaran bacaan/doa yang digunakan. Sementara itu, untuk mengukur pengetahuan siswa tentang materi tata cara pengurusan jenazah, digunakan evaluasi tes dengan menggunakan soal-soal pilihan ganda dan isian singkat berjumlah 20 nomor PG dan 5 nomor esai. Data hasil pengamatan keterampilan tata cara pengurusan jenazah dianalisis dengan menggunakan analisis deskriptif untuk mengetahui peningkatannya pada masing-masing siklus.

Untuk mengumpulkan data penelitian digunakan metode observasi dengan menggunakan instrumen lembar observasi untuk mengamati aktivitas belajar siswa. Untuk mengetahui hasil belajar, digunakan metode tes. Selain itu, sebagai pendukung, dilakukan dokumentasi selama proses pembelajaran berlangsung dengan meng-gunakan foto dan video.

\section{Hasil dan Pembahasan}

\section{Hasil}

\section{Pengetahuan Tata Cara Pengurusan Jenazah}

Proses belajar mengajar merupakan satu aktivitas khusus yang dilakukan oleh guru untuk menolong dan membimbing siswa memperoleh perubahan dan pengembangan, skill (keterampilan), attitude (sikap), appreciation (penghargaan) dan knowledge (pengetahuan) (Fatkhurrohman \& Sutikno, 2007). Pengetahuan (knowledge) dalam taksonomi Bloom masuk ke dalam ranah kognitif. Data ranah kognitif (pengetahuan) siswa pada materi tata cara pengurusan jenazah pada proses pembelajaran menggunakan metode VAK (Visualisation, Auditory, Kinestetic) diperoleh hasil sebagai berikut. 
Volume : 6

Nomor : 2

Bulan : November

Tahun : 2020

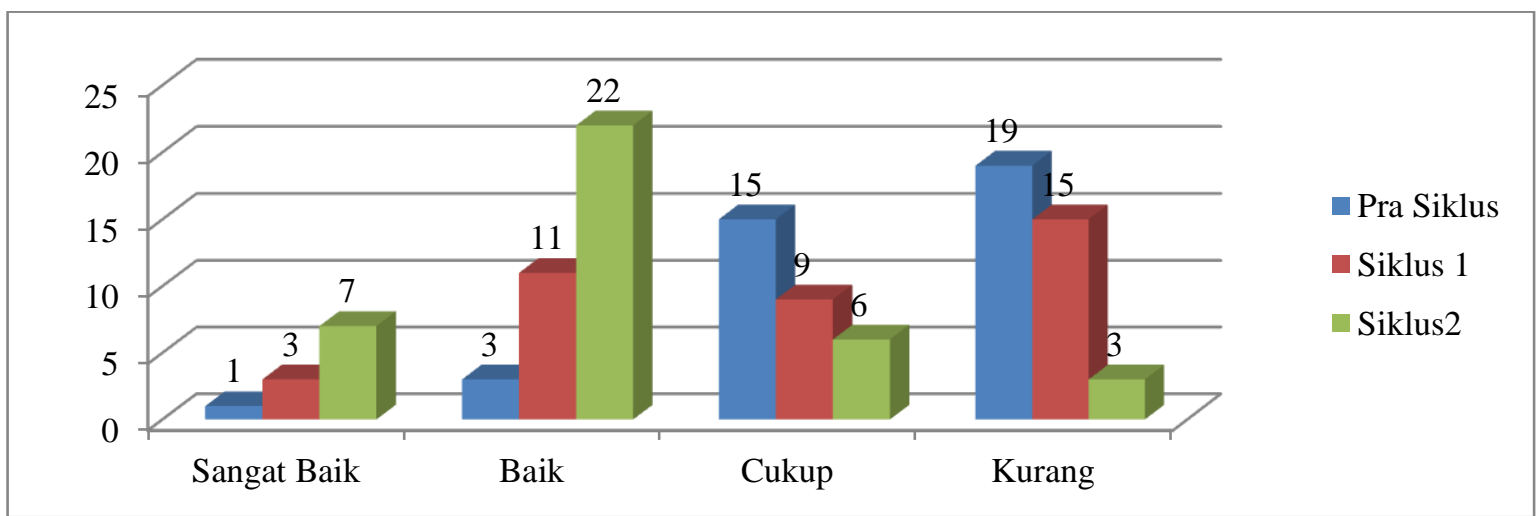

Gambar 1 Perbandingan Hasil Belajar dari Tahap Prasiklus, Siklus 1 dan Siklus 2

Pada tahap studi pendahuluan/prasiklus, jumlah siswa yang mencapai nilai ketuntasan (sama dengan atau lebih besar dari KKM [Kriteria Ketuntasan Belajar Minimal]) hanya berjumlah 18 orang dengan 1 orang mencapai nilai sangat baik (>90), 3 orang dengan nilai baik (75 $>X \leq 90)$, dan 15 orang dengan nilai sama dengan KKM (75) atau hanya 47,37\%. Pada tahap siklus 1, angka ketuntasan secara klasikal meningkat menjadi 60,53\% dan menjadi $92,11 \%$.

\section{Keterampilan Tata Cara Pengurusan Jenazah}

Pembelajaran merupakan proses yang diselenggarakan oleh guru untuk membelajarkan siswa dalam belajar bagaimana memperoleh dan memproses pengetahuan, keterampilan, dan sikap (Dimyati \& Mujiono, 2006). Keterampilan siswa diperoleh melalui serangkaian aktivitas belajar baik yang bersifat fisik maupun mental (Sardiman, 2011). Dalam kegiatan belajar mengajar,kedua hal ini adalah dua hal yang saling berkaitan dan tak terpisahkan. Sehingganya, Hamalik (2009) menyatakan aktivitas belajar sebagai kegiatan yang dilakukan oleh siswa dalam kegiatan pembelajaran. Dalam penelitian ini, aktivitas yang dimaksud adalah keterampilan yang dimiliki siswa pada materi tata cara pengurusan jenazah yang dilakukan secara berkelompok. Sehingganya, data keterampilan dinilai sebagai data kelompok. Berdasarkan hasil penelitian diperoleh data peningkatan keterampilan belajar kelompok sebagai berikut. 


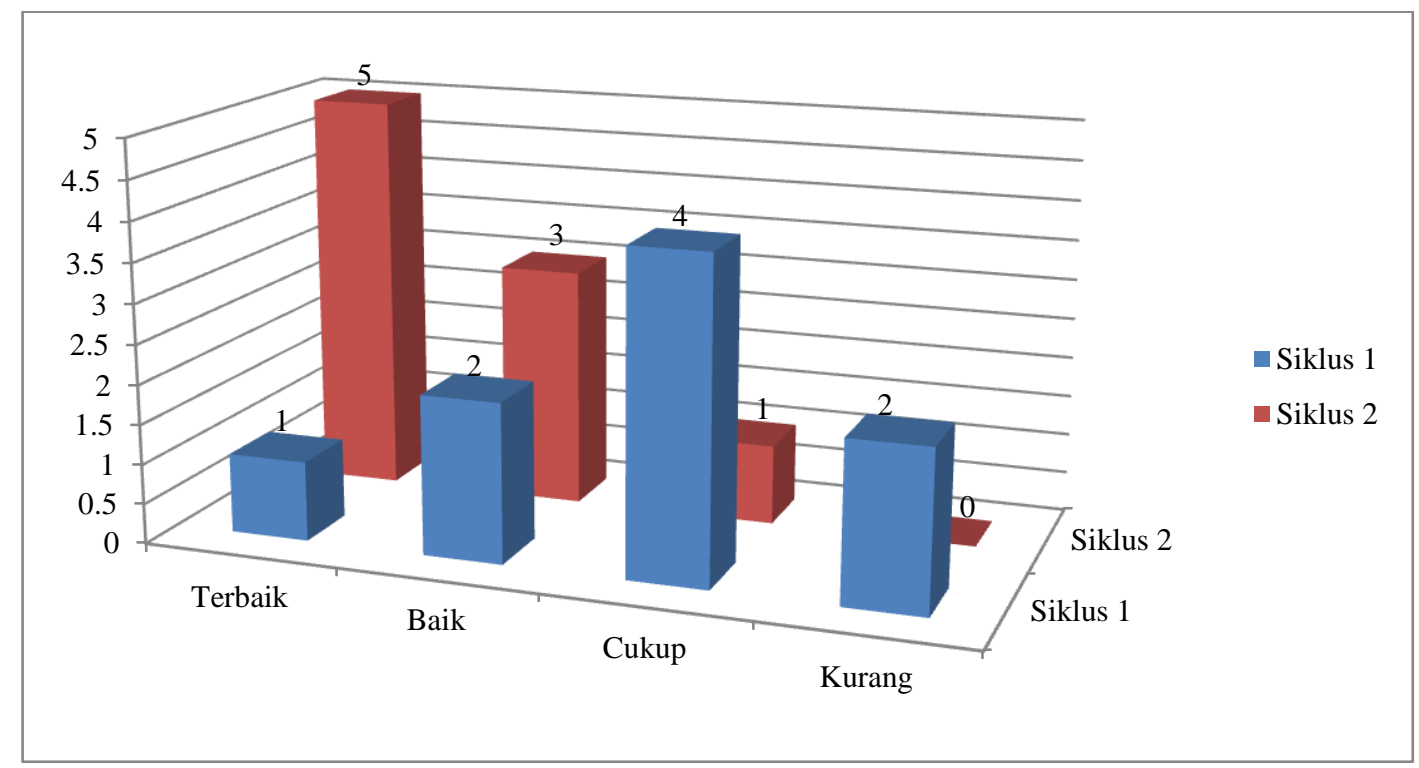

Gambar 2 Perbandingan Keterampilan Belajar Tata Cara Pengurusan Jenazah Antarkelompok pada Siklus 1 dan Siklus 2

Dari gambar di atas, terlihat bahwa jumlah kelompok yang masuk kategori terbaik (melakukan praktik tata cara pengurusan jenazah dengan sempurna sejak memandikan, mengafani, menyalatkan, dan menguburkan, serta benar dan lancar baik dalam langkahlangkah maupun bacaan/doa yang digunakan) meningkat dari satu kelompok pada siklus 1 menjadi lima kelompok pada siklus 2. Demikian juga untuk kelompok yang masuk kategori baik (mempraktikkan tata cara pengurusan jenazah sejak memandikan, mengafani, menyalatkan, dan menguburkan dengan benar meski kurang lancar, termasuk ketika membacakan doa-doa yang menyertai) juga meningkat dari 2 kelompok pada siklus 1 menjadi 3 kelompok pada siklus 2. Sebaliknya, untuk kelompok yang masuk kategori cukup (kurang lancar dan kurang tepat dalam mempraktikkan tata cara penurusan jenazah, serta doa-doa yang menyertai) dan kurang (melakukan praktik tata cara pengurusan jenazah dengan banyak kesalahan, baik pada langkah-langkah maupun pembacaan doa-doa yang mengiringi) mengalami penurunan dari siklus 1 ke siklus 2. Aspek kelancaran pada doa-doa yang digunakan pada setiap tahap dilihat pada dua aspek, yaitu kelancaran (tanpa kesalahan dan terbata), juga kebenaran secara makhrojul huruf (pengucapan huruf-huruf) yang diamati secara kelompok. 
Volume : 6

Nomor : 2

Bulan : November

Tahun : 2020

\section{Pembahasan}

\section{Pengetahuan Tata Cara Pengurusan Jenazah}

Metode pembelajaran Visualization, Auditory, Kinestetic (VAK) adalah metode pembelajaran yang mengoptimalkan tiga modalitas belajar, yaitu melihat, mendengarkan dan memahami nilai untuk menjadikan peserta didik merasa nyaman mengikuti kegiatan pembelajaran (Madjid, 2014). Dengan metode belajar ini, siswa diberikan kebebasan untuk menggunakan modalitas belajar yang mereka miliki. Dengan demikian, ketika seseorang merasa nyaman dan bisa menggunakan modalitas belajarnya dalam proses pembelajaran harapannya adalah hasil belajar mereka akan semakin meningkat.

Pada tahap studi pendahuluan/prasiklus, pengetahuan siswa tentang materi tata cara pengurusan jenazah masih rendah karena pada tahap ini siswa belum diberikan perlakuan/treatment apa pun. Hasil belajar yang terukur adalah pengetahuan awal peserta didik yang diperoleh dari jenjang pendidikan sebelumnya atau dari belajar dalam masyarakat (pendidikan informal). Pada siklus 1, hasil belajar sudah meningkat meskipun secara klasikal belum mencapai ketuntasan. Peningkatan hasil belajar pada siklus 1 salah satunya karena peserta didik sudah mendapatkan treatment/perlakuan, yaitu proses pembelajaran dengan mengoptimalkan tiga modalitas belajar (visual, auditori, dan kinestetik/praktik).

Peningkatan signifikan terjadi pada siklus 2 setelah ada repetisi dan pengulangan. Proses repetisi dan pengulangan akan semakin meningkatkan pemahaman peserta didik atas materi yang diajarkan. Ibarat kata pepatah, “Lancar kaji karena diulang, pasah jalan karena diturut.” Selain itu, peningkatan pengetahuan siswa tentang materi tata cara pengurusan jenazah juga didukung oleh motivasi belajar mereka yang meningkat karena merasa dilibatkan dalam proses pembelajaran. Perasaan dilibatkan membuat siswa menjadi lebih bergairah dan merasa bahwa pembelajaran yang dilakukan bermakna bagi mereka.

\section{Keterampilan Tata Cara Pengurusan Jenazah}

Kata "keterampilan" dalam Kamus Besar Bahasa Indonesia (KBBI) dimaknai sebagai kemampuan untuk melakukan kegiatan atau kerja. Pembahasan tentang keterampilan belajar sejatinya adalah proses yang kompleks. Dalam penelitian ini, keterampilan belajar dimaknai sebagai kerja kelompok terkait dengan materi yang sedang dibahas, yaitu tata cara pengurusan jenazah. Meskipun kewajiban pengurusan jenazah bersifat fardhu kifayah, pengetahuan serta

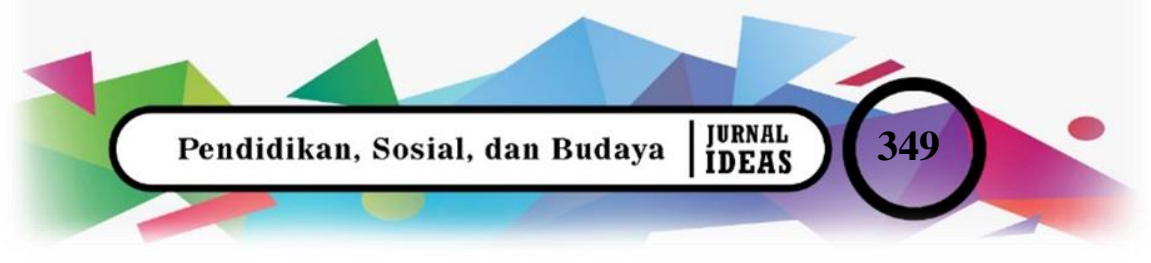


그 E-ISSH: 2656-940X

(D) P-ISSH: 2442-367K

URL:jurnal.ideaspublishing.co.id
Volume : 6

Nomor : 2

Bulan : November

Tahun : 2020

kemampuan melakukan pengurusan jenazah adalah materi Fikih yang penting untuk diajarkan. Hal itu karena setiap individu/siswa pasti akan dihadapkan pada peristiwa ini, baik itu yang menimpa orang terdekat, kerabat, maupun keluarga.

Fikih tata cara pengurusan jenazah harus dipahami dan dikuasai, baik oleh muslim maupun muslimah karena ada beberapa tahap yang bersifat khusus. Misalnya, memandikan jenazah wanita sebaiknya dilakukan oleh sesama wanita atau laki-laki yang mahramnya. Demikian pula jenazah laki-laki sebaiknya dimandikan oleh laki-laki, atau perempuan yang merupakan mahram si mayat. Dengan demikian, mengetahui dan menguasai tata cara pengurusan jenazah tidak dikhususkan untuk laki-laki saja atau perempuan saja, tetapi harus diajarkan kepada seluruh muslim, baik lakilaki maupun perempuan.

Pada tahap studi pendahuluan/prasiklus kebanyakan siswa masih bingung ketika ditanya tentang tata cara pengurusan jenazah. Kebanyakan menjawab selama ini mereka hanya mengikuti tahap menyalatkan jenazah sebagai makmum sehingga kurang memahami dengan baik bacaan yang digunakan dan hanya mengikuti gerakan imam. Demikian pula untuk proses memandikan, mengafani, dan menguburkan, rata-rata siswa mengaku hanya melihat belum pernah mempraktikkan.

Pada siklus 1 setelah perlakuan (menonton video tata cara pengurusan jenazah dan mendengarkan penjelasan guru), siswa diminta melakukan praktik tata cara pengurusan jenazah sejak memandikan, mengafani, menyalatkan, dan menguburkan. Sebagian besar kelompok sudah memahami, tetapi belum lancar melakukan, terutama pada doa-doa yang digunakan. Setelah dilakukan refleksi dan review materi pada siklus 2, sebgaian besar kelompok sudah mampu melakukan tata cara pengurusan jenazah dengan benar. Oleh karena itu, benar kiranya bahwa pembelajaran teori sebelum praktik itu penting agar bisa melakukan praktik dengan benar.

Kegiatan praktik sangat efektif untuk mencapai seluruh ranah pengetahuan secara bersamaan, antara lain melatih agar teori dapat diterapkan pada permasalahan yang nyata (kognitif), melatih perencanaan kegiatan secara mandiri (afektif), dan melatih penggunaan instrument tertentu (psikomotorik) (Rahayuningsih, 2005). Terkait dengan tata cara pengurusan jenazah, praktik pengurusan jenazah merupakan sarana mengaplikasikan pengetahuan (teori) yang telah didapat dan melatih kerja sama dalam kelompok. Selain itu, dengan praktik juga meningkatkan pengetahuan dan pemahaman siswa. 
Volume : 6

Nomor : 2

Bulan : November

Tahun : 2020

\section{Simpulan}

Berdasarkan hasil penelitian, terbukti bahwa dengan menggunakan metode visualisation, auditory, kinestetic (VAK) dapat meningkatkan pengetahuan dan keterampilan belajar siswa pada materi tata cara pengurusan jenazah. Penerapan metode ini juga meningkatkan motivasi dan semangat belajar siswa karena semua modalitas belajar siswa terwadahi. Metode VAK bisa dikembangkan untuk digunakan pada materi dan mata pelajaran lain utamanya yang tidak hanya mengukur ranah kognitif, tetapi juga keterampilan siswa.

\section{Daftar Pustaka}

Dimyati \& Mujiono. (2006). Belajar dan Pembelajaran. Jakarta: Rineka Cipta.

Fatkhurrohman, P., dan Sutikno, M. S. (2007). Strategi Belajar Mengajar. Bandung: PT Refika Aditama.

Hamalik, O. (2009). Kurikulum dan Pembelajaran. Jakarta: Bumi Aksara.

Harahap, M. A., Sinaga, A. I., dan Halimah, S. (2017). "Penerapan Strategi Pembelajaran Langsung dengan Metode Drill untuk Meningkatkan Aktivitas Belajar dan Keterampilan Pelaksanaan Ibadah Pokok Bahasan Pengurusan Janazah di MTs Al-Ma'shum Rantauprapat Labuhanbatu". Edu Riligia, 1(3).

Jarvis, M. (2012). Teori-Teori Psikologi. Jakarta: Nusa Media.

Madjid, A. (2014). Model-Model Pembelajaran. Bandung: Alfabeta.

Rahayuningsih, E., dan Dwiyanto, D. (2005). Pembelajaran di Laboratorium. Yogyakarta: Pusat Pengembangan Pendidikan Gadjah Mada.

Sardiman, A. M. (2011). Interaksi dan Motivasi Belajar Mengajar. Jakarta: Rajawali. Sugiyanto. (2008). Model dan Metode Pembelajaran Kooperatif. Jakarta: Praya Media.

Syahidah, N. L. (2020). "Metode Demonstrasi pada Pembelajaran PAI (Studi Kasus Materi Penyembelihan Hewan dan Pengurusan Jenazah)". Edudeena: Journal of Islamic Religious Education, 4(1), 49-58. 
DE-ISSH: 2656-940X $2442-367 X$

URL: jurnal.ideaspublishing.co.id

Volume : 6

Nomor : 2

Bulan : November

Tahun : 2020 